\title{
TO STUDY THE BLENDS OF EPDM RUBBER WITH LDPE
}

\author{
MODAN RIYAZ Y ${ }^{1}$, R.N.DESAI ${ }^{2}$ \\ L.D. College of Engineering, Ahmedabad-380015, riyazmodan@yahoo.com,rupandendesai@yahoo.com
}

\begin{abstract}
Several formulations containing EPDM and LDPE were prepared. EPDM was blended with LDPE in different weight ratios of LDPE/EPDM (40/60, 30/70, 20/80, 10/90). These compounds were mixed at $150^{\circ} \mathrm{C}$ in open mill for 10 min at a speed of $19.03 \mathrm{rpm}$ and then mixed with phenolic resin. Here, phenolic resin grade SP-1068 used which work as a tackifier resin. The mechanical, thermal, morphological, dynamical and electrical properties of polymeric insulators will be tested and reported in thesis. In future, the result of mechanical measurement shows that mechanical properties such as tensile strength, modulus and elongation-at-break of blends can be enhanced with increase in LDPE in the formulation. Also tests will be conducted to study various properties (mechanical, surface, electrical) under accelerated ageing condition. Because the life time of these compounds are generally too long to wait for a verdict on their behavior in use.
\end{abstract}

Key words - EPDM, LDPE, Phenolic resin sp-1068, Mechanical properties

$* * *$

\section{INTRODUCTION}

Ethylene-propylene rubbers \& elastomers (also called EPDM and EPM) continue to be one of the most widely used and fastest growing synthetic rubbers having both specialty and general-purpose applications. Sales have grown to 870 metric tons (or 1.9 billion pounds) in 2000 since commercial introduction in the early 1960's.Polymerization and catalyst technologies in use today provide the ability to design polymers to meet specific and demanding application and processing needs. Versatility in polymer design and performance has resulted in broad usage in automotive weather-stripping and seals, glass-run channel, radiator, garden and appliance hose, tubing, belts, electrical insulation, roofing membrane, rubber mechanical goods, plastic impact modification, thermoplastic Vulcanizate and motor oil additive applications.

Ethylene-propylene rubbers are valuable for their excellent resistance to heat, oxidation, ozone and weather aging due to their stable, saturated polymer backbone structure. Properly pigmented black and non-black compounds are color stable. As non-polar elastomers, they have good electrical resistivity, as well as resistance to polar solvents, such as water, acids, alkalies, phosphate esters and many ketones and alcohols. Amorphous or low crystalline grades have excellent low temperature flexibility with glass transition points of about minus $60^{\circ} \mathrm{C}$.Heat aging resistance up to $130^{\circ} \mathrm{C}$ can be obtained with properly selected sulfur acceleration systems and heat resistance at $160^{\circ} \mathrm{C}$ can be obtained with peroxide cured compounds. Compression set resistance is good, particularly at high temperatures, if sulfur donor or peroxide cure systems are used.

\section{KEY FEATURES OF ETHYLENE-PROPYLENE ELASTOMERS}

Vistalon 7001 EPDM rubber is a tailored MWD, high ethylene and medium diene polymer produced using ExxonMobil Chemical's EXXPOL ${ }^{\mathrm{TM}}$ Technology for precise control of molecular composition and architecture. This product is sold in pellet form.

\section{Key Features}

Designed for good physical properties, improved mixing, mill handling and extrusion compared to typical narrow MWD grades.

\begin{tabular}{|l|c|c|c|}
\hline Physical & $\begin{array}{l}\text { Typical } \\
\text { Value } \\
\text { (English) }\end{array}$ & $\begin{array}{l}\text { Typical } \\
\text { Value } \\
\text { (SI) }\end{array}$ & $\begin{array}{l}\text { Test Based } \\
\text { On }\end{array}$ \\
\hline $\begin{array}{l}\text { Mooney } \\
\text { Viscosity } \\
\text { ML 1+4, } \\
\left.257^{\circ} \mathrm{F}\left(125^{\circ} \mathrm{C}\right)\right)\end{array}$ & MU & MU & ASTM D1646 \\
\hline $\begin{array}{l}\text { Ethylene } \\
\text { Content }\end{array}$ & $\begin{array}{l}73.0 \\
\text { wt\% }\end{array}$ & $\begin{array}{l}73.0 \\
\text { wt\% }\end{array}$ & ASTM D3900 \\
\hline $\begin{array}{l}\text { Ethylidene } \\
\text { norbornene } \\
\text { (ENB) Content }\end{array}$ & $\begin{array}{l}5.0 \\
\text { wt } \%\end{array}$ & $\begin{array}{l}5.0 \\
\text { wt } \%\end{array}$ & ASTM D6047 \\
\hline
\end{tabular}




\section{LOW-DENSITY POLYETHYLENE}

LDPE is defined by a density range of $0.910-0.940 \mathrm{~g} / \mathrm{cm} 3$. It is not reactive at room temperatures, except by strong oxidizing agents, and some solvents cause swelling. It can withstand temperatures of $80{ }^{\circ} \mathrm{C}$ continuously and $95^{\circ} \mathrm{C}$ for a short time. Made in translucent or opaque variations, it is quite flexible, and tough but breakable.

LDPE has more branching (on about $2 \%$ of the carbon atoms) than HDPE, so its intermolecular forces (instantaneous-dipole induced-dipole attraction) are weaker, its tensile strength is lower, and its resilience is higher. Also, since its molecules are less tightly packed and less crystalline because of the side branches, its density is lower. LDPE contains the chemical elements carbon and hydrogen.
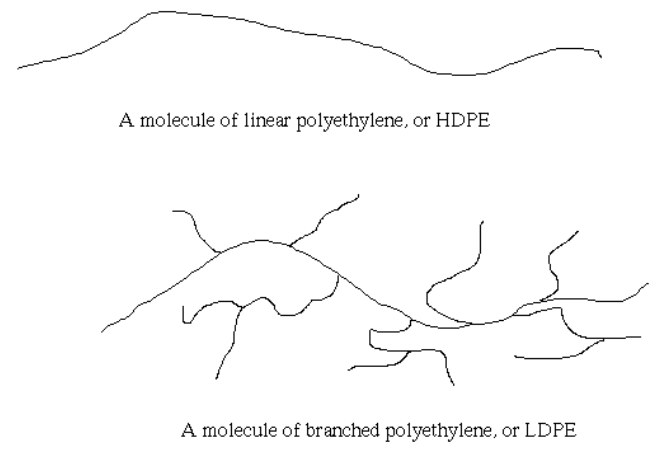

Figure1: HDPE AND LDPE structure

\section{Chemical resistance}

- Excellent resistance (no attack) to dilute and concentrated acids, alcohols, bases and esters. Good resistance (minor attack) to aldehydes, ketones and vegetable oils. Limited resistance (moderate attack suitable for short-term use only) to aliphatic and aromatic hydrocarbons, mineral oils, and oxidizing agents. Poor resistance, and not recommended for use with Halogenated hydrocarbons.

\subsection{Variations of Polymer Blend Properties}

The properties of polymer blends may vary depending on several contributing factors which are interdependent. Alger and Dyson (1990) list and summarize the factors as follow:

1) Type of polymers;

2) Composition;

3) Compatibility

4) Phase morphology;

5) Method of blend preparation.

\section{Type of Polymers}

Elastomers or rubbers are polymers that may be deformed to quite large deformations and return to their original dimension once the stress is removed. In the absence of stress, elastomers are amorphous and contain molecular chains that are highly twisted, kinked, and coiled. Elastic deformation in elastomers represents partial uncoiling, untwisting and straightening of chains in the stress direction and the chains return to their original position once the stress is removed. Generally, elastomers posses the following characteristics:

i) not easily crystallize;

ii) their chain bond rotations are relatively free in order for the coiled chains to readily respond to an applied force;

iii) And the onset of plastic deformation is delayed in order to experience a large elastic deformation.

\section{Composition}

The properties of polymer blends may vary depending on their compositions. The variations of properties are due to the changes in phase structure related to the composition. Variation in composition may affect phase morphology of polymer blends. For example, the polymer with higher concentration forms a continuous phase. In order to prevent phase separation and hence negatively affects the blend properties, the discontinuous phase of the other polymer blend constituent must have a small particle size.

\section{Compatibility}

Compatibility of polymer blends may refer to the ability of two or more polymers to exist in close and permanent association resulting in useful properties regardless of whether they are theoretically miscible or immiscible. Miscibility by itself is not the paramount criteria for utility. For instance, immiscibility is useful in the impact modification of relatively brittle polystyrene by rubber whereby energy absorption results from crazing of the polystyrene matrix in the region between the rubber particles.

\section{Phase Morphology}

Morphology is the order or arrangement of the polymer structure. The possible range of order between a molecule or molecule segment and its neighbors can vary from a very ordered highly crystalline polymer structure to the highly disordered amorphous structure as shown on the left side of Figure. The semi-crystalline polymer blends is formed by a combination of amorphous and crystalline structures as shown in the middle of the figure. It can be captured with an electron 


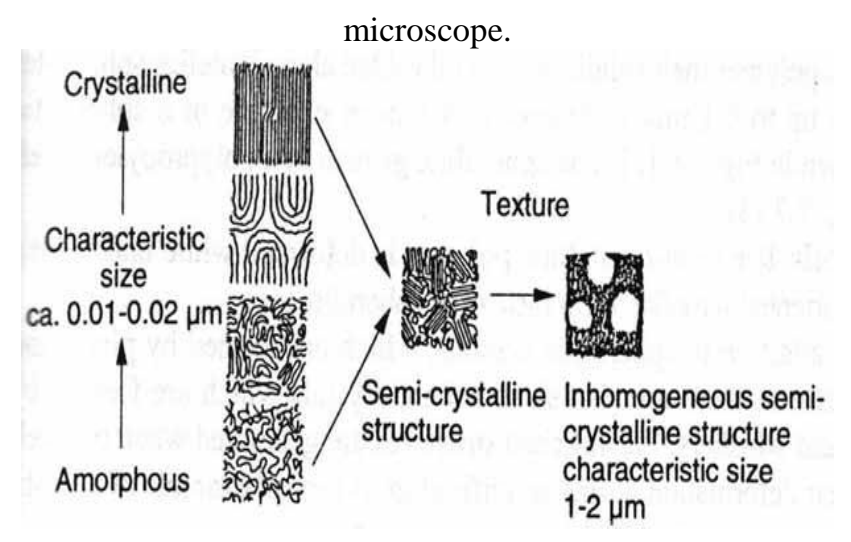

Fig:-2 Schematic diagram of possible molecular structure which normally occurs in thermoplastics

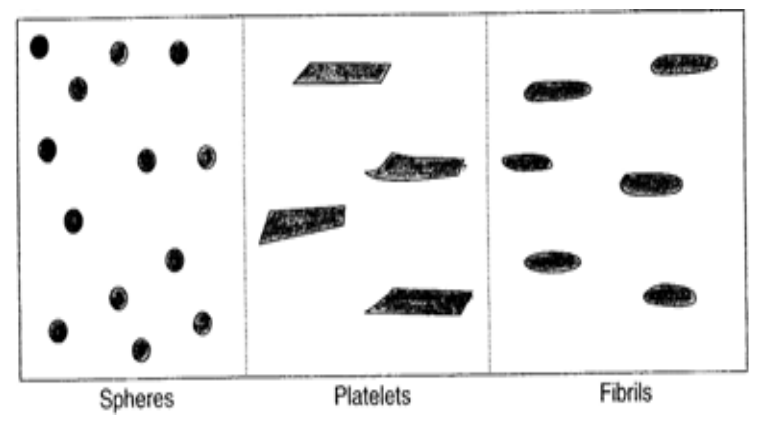

Fig:-3Different morphologies exhibited by immiscible blends of polymers

\section{Method of Blend Preparation}

Polymer blends may be prepared by the following methods:

i) Mechanical blending;

ii) Dissolution in co-solvent then film casting, freeze or spray drying;

iii) Latex blending;

iv) Fine powders mixing;

v) Inter-penetrating polymer network technology. Due to economic reasons, the mechanical mixing predominates. The mechanical blending of polymers can be performed using a tworoll mill, internal mixer or extruder. In this research work, the blending process of LDPE/EPDM involves the use of a two roll mill.

\section{EXPERIMENTAL STUDIES}

\subsection{Identification of materials}

\begin{tabular}{|l|l|l|}
\hline Material & Grade & Supplier \\
\hline EPDM & Vistalon 7001 & Exxon Chemical \\
\hline LDPE & Reliance & Reliance \\
& 24 FS040 & Petrochemical \\
& & \\
\hline
\end{tabular}

\subsection{Compound formula}

Sample1. (EPDM:-60\%, LDPE:-40\%)

\begin{tabular}{|c|c|c|c|c|}
\hline Ingredients & $\begin{array}{c}\text { Weight } \\
\text { ratio(gm) }\end{array}$ & $\begin{array}{l}\text { Mixing } \\
\text { time }\end{array}$ & $\begin{array}{l}\text { Mixing } \\
\text { temp. }\end{array}$ & $\begin{array}{l}\text { Roll } \\
\text { Spd. }\end{array}$ \\
\hline $\begin{array}{l}\text { Vistalon7001 } \\
\text { EPDM }\end{array}$ & 144 & \multirow[t]{4}{*}{10 mins } & \multirow[t]{4}{*}{$150^{\circ} \mathrm{C}$} & \multirow{4}{*}{$\begin{array}{l}19.0 \\
3 \\
\mathrm{rpm}\end{array}$} \\
\hline LDPE & 96 & & & \\
\hline $\begin{array}{l}\text { Phenolic resin } \\
\text { SP-1068 }\end{array}$ & 48 & & & \\
\hline Zno & 12 & & & \\
\hline
\end{tabular}

Sample2. EPDM:-70\%, LDPE:-30\%

\begin{tabular}{|l|l|l|l|l|}
\hline Ingredients & $\begin{array}{c}\text { Weight } \\
\text { ratio(gm) }\end{array}$ & $\begin{array}{l}\text { Mixing } \\
\text { time }\end{array}$ & $\begin{array}{l}\text { Mixing } \\
\text { temp. }\end{array}$ & $\begin{array}{l}\text { Roll } \\
\text { Spd. }\end{array}$ \\
\cline { 1 - 2 } $\begin{array}{l}\text { Vistalon 7001 } \\
\text { EPDM }\end{array}$ & 168 & $\begin{array}{l}12 \\
\text { mins. }\end{array}$ & $150^{\circ} \mathrm{C}$ & $\begin{array}{l}19.0 \\
3\end{array}$ \\
\cline { 1 - 2 } LDPE & 72 & & & \\
\cline { 1 - 2 } $\begin{array}{l}\text { Phenolic } \\
\text { resin SP-1068 }\end{array}$ & 48 & & & \\
\cline { 1 - 2 } Zno & 12 & & & \\
\hline
\end{tabular}

Sample3. EPDM:-80\%, LDPE:-20\%

\begin{tabular}{|l|c|l|l|l|}
\hline Ingredients & $\begin{array}{c}\text { Weight } \\
\text { ratio(gm) }\end{array}$ & $\begin{array}{l}\text { Mixing } \\
\text { time }\end{array}$ & $\begin{array}{l}\text { Mixing } \\
\text { temp. }\end{array}$ & $\begin{array}{l}\text { Roll } \\
\text { Spd. }\end{array}$ \\
\cline { 1 - 2 } $\begin{array}{l}\text { Vistalon 7001 } \\
\text { EPDM }\end{array}$ & 192 & 15 mins & $150^{\circ} \mathrm{C}$ & $\begin{array}{l}19.0 \\
3\end{array}$ \\
\cline { 1 - 2 } LDPE & 48 & & & rpm \\
\cline { 1 - 2 } $\begin{array}{l}\text { Phenolic resin } \\
\text { SP-1068 }\end{array}$ & 48 & & & \\
\hline Zno & 12 & & & \\
\hline
\end{tabular}

Sample4. EPDM:-90\%, LDPE:-10\%

\begin{tabular}{|l|l|l|l|l|}
\hline Ingredients & $\begin{array}{c}\text { Weight } \\
\text { ratio(gm) }\end{array}$ & $\begin{array}{l}\text { Mixing } \\
\text { time }\end{array}$ & $\begin{array}{l}\text { Mixing } \\
\text { temp. }\end{array}$ & $\begin{array}{l}\text { Roll } \\
\text { Spd. }\end{array}$ \\
\hline $\begin{array}{l}\text { Vistalon 7001 } \\
\text { EPDM }\end{array}$ & 216 & $\begin{array}{l}20 \\
\text { mins }\end{array}$ & $150^{\circ} \mathrm{C}$ & $\begin{array}{l}19.03 \\
\text { rpm }\end{array}$ \\
\cline { 1 - 2 } LDPE & 24 & & & \\
\cline { 1 - 2 } $\begin{array}{l}\text { Phenolic } \\
\text { resin } \\
\text { SP-1068 }\end{array}$ & 48 & & & \\
\cline { 1 - 2 } Zno & 12 & & & \\
\hline
\end{tabular}

Several formulations containing EPDM and LDPE were prepared (Table). EPDM was blended with LDPE in different weight ratios of LDPE/EPDM (40/60, 30/70, 20/80, 10/90). These compounds were mixed at $150^{\circ} \mathrm{C}$ in open mill for 10 min, $12 \mathrm{~min}, 15 \mathrm{~min}$, and $20 \mathrm{~min}$ at a speed of $19.03 \mathrm{rpm}$ and then mixed with phenolic resin and zno. 
The mixing machine open roll mill was heated to 150.c and kept constant before used .LDPE was first introduced into mixing mill. When it was totally melted, compatibilizer and rubber were added consecutively. The blend then was mixed within 10 mins to 20 mins which depend upon the types of formation and compression molded using at 150.c, in 12 mins into sheets approximately $1 \mathrm{~mm}$ thick with hot pressing equipment. Finally, the resulting sheet was cooled down quickly by cold water to ambient temperature.

\section{RESULTS AND DISCUSSION}

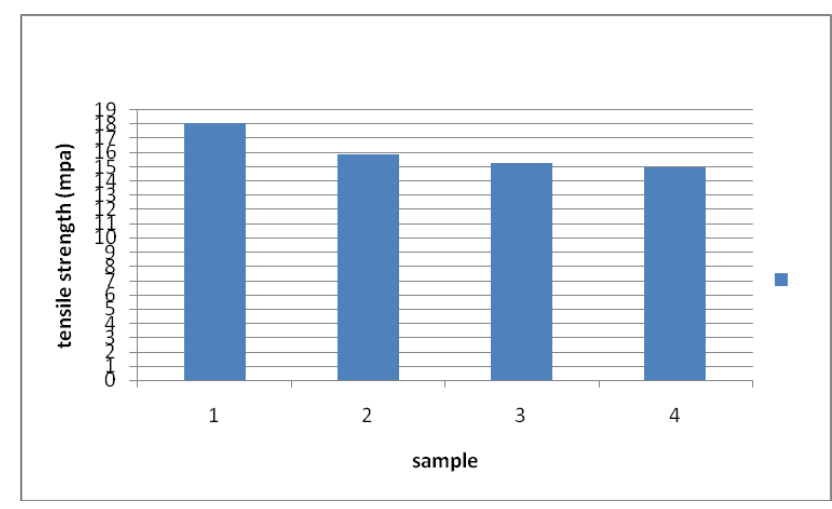

Fig:-4 Comparison of the tensile strength value for samples.

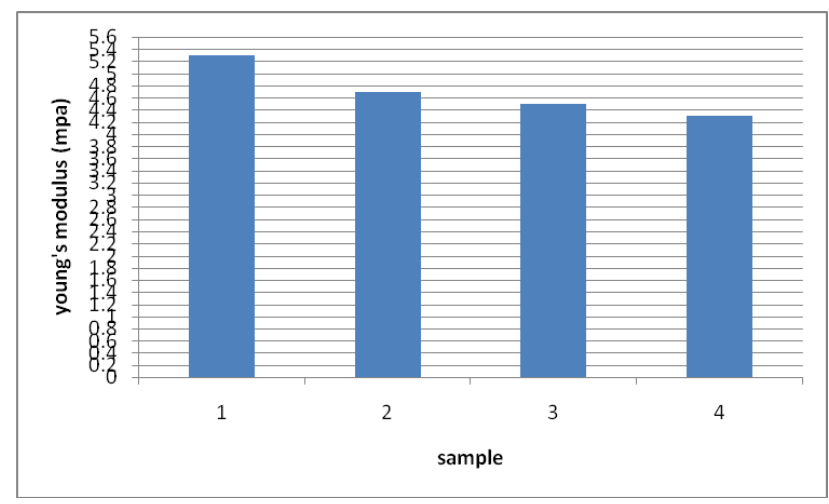

Fig:-5 Comparison of the young's modulus value for samples.

It can be seen from the result that SP 1068 resin was good compatibilizer in EPDM rubber. Dosage of LDPE increased then tensile strength and young modulus increased but percentage of resin also important for mechanical properties. Higher percentage of resin couldn't effect to properties. So nearly $2-2.5 \%$ resin added in polymer blends. Young's modulus were improved as increased the content of non reactive compatibilizer agent was increased. The rubber-rich blends can be used as thermoplastic elastomers and the plastic-rich blends can be used as rubber toughened plastics. Processing and final properties are dependent on the composition

\section{CONCLUSIONS}

Due to unsaturated bonds the extent of cross-linking in EPDM is much higher than LDPE in the presence of resin. The mechanical properties of cross-linked EPDM are weaker than LDPE. Therefore, changing the cross-link density of EPDM will not affect the blend properties significantly especially at high LDPE content. It can be observed that mechanical properties such as tensile strength, modulus and elongation-at-break increase with increasing LDPE content in the samples, implying that the phase of matrix governs the properties

\section{REFERENCES}

[1]. Manzur A Olayo R, Ramos E, Effect of EPDM on LPDE/LLDPE blends mechanical properties, J Appl Polym Sci, 65, 4, 677-683, 1998.

[2]. Sadek EM, Ei-Nashar DE, Motawie AM, Modification of ethylene propylene diene terpolymer rubber by some thermoplastic polymers, polym-Plast technol Eng, 42, 627-642, 2003.

[3]. Show MT, Olabisi ), Robeson LM (Eds), Polymer-Polymer Miscibility, Academic, London, 1979.

[4]. Ehsani M, Borsi H, Bakhshandeh Gr, Morshedian J, An investigation of dynamic mechanical, thermal, an electrical properties of housing materials for outdoor polymeric insulators, Adv Polym Technol, 24, 51-61, 2005.

[5]. Batiuk M, herman RM, Healy JC, Thermoplastic polymers blends of (1) EPDM having a high degree of unstretched crystallinity with (2) polyethylene , US Patent 3, 919, 358, 1975 [6]. Richard Karpeles and Anthony V. Grossi, "EPDM Rubber Technology", Handbook of Elastomers, 2ndEd., Anil K. Bhowmick and Howard L. Stephens [Editors], pp. 845-876, Marcel Decker, Inc., New York (2001).

[7]. John A. Riedel and Robert Vander Laan, "Ethylene Propylene Rubbers", The Vanderbilt Rubber Handbook, 13th Ed., pp. 123-148, R.T. Vanderbilt Co., Inc., Norwalk, CT (1990).

[8] .Gary Ver Strate, "Ethylene PropyleneElastomers", Encyclopedia of Polymer Science \& Engineering, vol. 6, pp. 522-564 (1986). 